Correction

\title{
Correction: Ha, Y. et al. Hemispherical Microelectrode Array for Ex Vivo Retinal Neural Recording. Micromachines 2020, 11, 538
}

\author{
Yoonhee Ha ${ }^{1}$, Hyun-Ji Yoo ${ }^{1}$, Soowon Shin ${ }^{2}$ and Sang Beom Jun ${ }^{1,3, *(D)}$ \\ 1 Department of Electronic and Electrical Engineering, Ewha Womans University, Seoul 03760, Korea; \\ yoonhee0127@gmail.com (Y.H.); dibbe@ewhain.net (H.-J.Y.) \\ 2 Department of Bioengineering, TODOC Co., Ltd., Seoul 08394, Korea; swshin@to-doc.com \\ 3 Department of Brain and Cognitive Sciences, Ewha Womans University, Seoul 03760, Korea \\ * Correspondence: juns@ewha.ac.kr; Tel.: +82-2-3277-3892
}

Received: 14 July 2020; Accepted: 21 July 2020; Published: 24 July 2020

The authors would like to make the following changes to the published paper [1]: the ethic code in the last line of Section 2.8.1 (page 8) should be "IACUC 19-025":

"The experimental procedures and the care of the animals were approved by the Institutional

Animal Care and Use Committee (IACUC) of EwhaWomans University (IACUC 19-025)."

The change does not affect the scientific results. The manuscript will be updated and the original version will remain online on the article webpage with a reference to this correction.

\section{Reference}

1. Ha, Y.; Yoo, H.-J.; Shin, S.; Jun, S.B. Hemispherical Microelectrode Array for Ex Vivo Retinal Neural Recording. Micromachines 2020, 11, 538. [CrossRef] [PubMed]

(C) 2020 by the authors. Licensee MDPI, Basel, Switzerland. This article is an open access article distributed under the terms and conditions of the Creative Commons Attribution (CC BY) license (http://creativecommons.org/licenses/by/4.0/). 